\title{
Urban consolidation centres: retail stores demands for UCC services
}

Henrik J ohansson and Maria Björklund

The self-archived postprint version of this journal article is available at Linköping University Institutional Repository (DiVA):

http:/ / urn.kb.se/ resolve?urn=urn:nbn:se:liu:diva-140529

N.B.: When citing this work, cite the original publication.

J ohansson, H., Björklund, M., (2017), Urban consolidation centres: retail stores demands for UCC services, International J ournal of Physical Distribution \& Logistics Management, 47(7), 646-662. https:/ doi.org/ 10.1108/ IJ PDLM-02-2017-0114

Original publication available at:

https:/ / doi.org/ 10.1108/ IJ PDLM-02-2017-0114

Copyright: Emerald

http:// www.emeraldinsight.com/ 


\title{
Urban Consolidation Centres:
}

\section{Retail stores' demands for UCC-services}

\begin{abstract}
Purpose Urban consolidation centres (UCCs) are often conceived to improve services in retail stores and potentially reduce costs. However, few studies have examined how retail stores perceive the services a UCC could provide. The purpose of this article is to explore retail stores' potential demands for different services that a UCC could provide in order to foster the development and implementation of UCC solutions aimed towards more economically feasible business models.
\end{abstract}

Design/methodology/approach Structured interviews were conducted with employees at 72 retail stores. Qualitative, as well as quantitative analyses, were conducted to identify the potential demands of the retail stores.

Findings We have provided arguments why retail stores might be interested in UCC services, and thereby potentially pay for them. Improved customer service to stores’ customers might not be a valid argument. We point to the cost aspect: stores expend resources that a UCC could provide in a more cost-efficient manner.

Research limitations/implications The findings contradict previous studies to some extent, as it indicates that a UCC may actually not enhance customer service in retail stores. Instead, our findings point to the importance of considering the potential advantages according to economies of scale that are facilitated by UCC services.

Practical limitations/implications Taking the perspective of the stores is important in order to identify arguments for why they should pay for the services provided by a UCC. 
Social implications: Financially viable UCC solutions are needed in order for the initiatives to be maintained and thereby provide a long-term decrease in the environmental and social footprint caused by urban freight.

Originality/value This study answers the call for research addressing retailers’ perspective in urban logistics, as it takes a demand-driven perspective of the development of UCC services. Furthermore, by highlighting services requested by retail stores, it can guide the financing of UCC initiatives, an aspect that has been lacking.

Keywords city logistics, receivers, customer service, urban distribution, business model, urban freight

Paper type Research paper 


\section{Introduction}

According to a report from the United Nations (United Nations, 2014), the bulk of the world's population growth is expected to occur in cities. With the increasing numbers of city-dwellers and the resulting urban expansion, the demand for urban freight deliveries is also increasing, which, although necessary, affects cities in negative ways (Liimatainen et al., 2015) including air pollution, noise pollution, and traffic congestion (Browne and Gomez, 2011; Allen et al., 2015).

Numerous initiatives have appeared on cities' agendas with the aim of decreasing the impact of freight deliveries on urban environments. One of these is the use of urban consolidation centres (UCCs) (Muñuzuri et al., 2005). According to Browne et al. (2005), a UCC is a facility that connects long-haul transport with deliveries to stores and offices, among other destinations, located in urban areas. With UCCs, long-haul transport by large vehicles designed for regional transport never has to enter the urban area. Furthermore, the consolidation of goods at UCCs can reduce the number of long-haul transport vehicles within the city area by substituting smaller vehicles more suitable for urban deliveries. Such consolidation can also result in better resource utilization through higher fill rates in city distribution.

A large number of UCCs have been implemented worldwide during the last two decades. In most cases, funding for these centres has been provided by public authorities, and when financial support from the authorities decreases or is withdrawn, the initiatives are often terminated (Ville et al., 2013; Quak et al., 2014). Related to this, Malhene et al. (2012) state, "The fragility of the business model of urban distribution platforms is in the heart of the difficulties met by UCC initiatives” (Malhene et al., 2012, pg. 4). According to Allen et al. (2012), other stakeholders - for example, retail stores, carriers, and other receivers besides retail stores-must contribute financially to UCCs. Allen et al. (2012) have pointed out that 
UCCs, which serve large sites with a single landlord benefit from the landlord's capacity to require tenants to use the UCC and to pay for it. Accordingly, as the first step in this study, we focus on single-landlord sites, i.e. city malls.

Among the benefits a UCC can provide for its customers, i.e. the UCC's customers (in this study, the retail stores), Browne et al. (2011) have identified logistics and value-added services. These services include improved reverse logistics, fewer deliveries, additional stockholding, better inventory control, preparation of products, and greater consignment (Browne et al., 2005; van Rooijen and Quak, 2010). In this article, we refer to all potential services that a UCC can provide as UCC services. With the use of these services, retail stores can focus on their core activities and potentially increase customer service in their stores. However, even if UCC services can improve retail stores' service for their customers, whether retail stores have any interest in those UCC services remains unclear. One way to identify a potential interest is to address retail stores experience problems in their daily work that UCC services can help to solve. In response, the purpose of this article is to explore retail stores' potential demands for different services that a UCC can provide in order to foster the development and implementation of UCC solutions aimed towards more economically feasible business models.

\section{Literature review}

Although numerous, the definitions and descriptions of UCCs are rather similar. With minor variations, a UCC is 'a logistics facility that is situated in relative proximity to the geographic area that it serves, be that a city centre, an entire town, or a specific site (e.g. shopping centre) from which consolidated deliveries are carried out within that area' (Browne et al., 2005, pg. 4). Although Ville et al. (2013) use the same definition, theirs adds public authorities as UCCs' frequent financial providers. A similar definition is that UCCs 'include all initiatives that use a facility, in which flows from outside the city are consolidated with the objective to bundle inner- 
city transport activities’ (van Rooijen and Quak, 2010, pg. 5968). Inspired by these definitions, we define a UCC as a logistics facility that serves a city area, either partially or entirely, and whose inflows from outside the city are consolidated and rearranged in order to provide moreefficient transport within the city. With UCC customers, all potential stakeholders that could benefit from the use of a UCC are considered, but in this study, the focus is on retail stores.

\section{Pros and cons of UCCs}

The implementation of a UCC influences how goods are distributed within a city, and by consolidating goods at a UCC, a greater opportunity arises to achieve higher fill rates for vehicles entering the urban area, due primarily to more-effective loading (Browne et al., 2005). As a result of increased fill rates, having fewer transports in the urban area becomes possible (Browne et al., 2005; BESTUFS, 2007). A UCC can also facilitate changes in the transport modes applied. As both Browne et al. (2005) and van Rooijen and Quak (2010) have posited, last-mile deliveries can be performed by either smaller or more environmentally friendly vehicles.

According to Browne et al. (2005), a city can benefit in multiple ways, both environmental and social, by implementing a UCC. Among the most common advantages are reduced emissions, decreased noise, less traffic congestion, and fewer traffic accidents, all due to fewer freight vehicles being in the urban area. Björklund and Gustafsson (2015) put forward additional benefits of using a UCC including a safer environment for receivers because of a reduction in heavier trucks and improved delivery service and work environments for receivers. With more environmentally friendly vehicles, the environmental benefits could be even greater. Yet a notable drawback, at least from a social perspective, is the increased traffic near a UCC due to increased inbound freight transport (Browne et al., 2005). In that sense, the placement of a UCC is critical. 
However, the potential economic advantages of a UCC are not as clear as the environmental and social benefits, and several initiatives readily demonstrate economic disadvantages. For one, a UCC poses a set-up cost and, later, operational costs for running the UCC (Browne et al., 2005). Examples of cost components for a UCC are personnel, electricity and power, increased administration and handling, maintenance, and rent (see e.g. Marcucci and Danielis, 2007; Browne et al., 2011; Lin et al., 2014; Rao et al., 2015). Due to consolidation, the UCC can facilitate more-efficient outbound transports and can, thereby, reduce costs such as those related to fuel, insurance, maintenance, and drivers (Browne et al., 2011). This is also in line with the study by (Nordtømme et al., 2015), who state that a UCC costs money, but it can also lead to cost reductions. It is of significant importance that the costs are balanced towards the benefits expressed in environmental, social, and economic terms (Allen et al., 2014). Malhene et al. (2012) have concluded that the chief obstacle of UCCs is their fragile business model, if not their complete lack of one, which seems to be a common theme in urban logistics initiatives. As Quak (2011) has posited, many urban logistics initiatives focus on technical, environmental, and operational feasibility (e.g. emission-free vehicles), while the consideration of economic feasibility is often weak or even absent. As such, urban logistics solutions suffer from a failure to present viable business opportunities (Aastrup et al., 2012), which are nevertheless necessary for securing financial feasibility in order to achieve long-term success. Moreover, UCCs are costly to set up and operate. As examples worldwide have demonstrated, when governmentseither local, regional, or national—have to account for these expenses, most pilot UCCs have been shut down when financing ends (Quak et al., 2014).

\section{Benefits for the receivers by using a UCC}

Another aspect of financing UCCs involves who should pay for them and why - that is, who can gain from UCCs and in what ways. Quak et al. (2014) have argued that among the potential stakeholders, the willingness to invest depends on the benefits that each actor can expect to 
receive. For example, van Rooijen and Quak (2010) describe previous initiatives that have focused on carriers, who actually gain few benefits from using UCCs. Other city logistics stakeholders that can benefit from the implementation of a UCC but have not yet been addressed in regard to the financing of a UCC are the senders and real-estate owners. However, considering their potential to receive UCC services designed to meet their specific needs, the stakeholder group that might have the most to gain from the implementation of a UCC is the receivers. For instance, the Binnenstadt service initiative in the Netherlands is, to a large extent, built on the idea that receivers should contribute to financing the UCC since they benefit from using many of the services that the UCC provides (van Rooijen and Quak, 2010). As mentioned in the introduction, we use the term UCC services for all potential logistics and value-added services made possible by implementing a UCC.

A change in delivery patterns can result in several benefits for receivers served by UCCs. In their review of documented UCCs worldwide, Browne et al. (2005) found that a UCC can provide receivers with more-flexible deliveries and more-reliable delivery times. More precisely, more-flexible deliveries imply both more-flexible delivery times and changes in delivery frequency. Aastrup et al. (2012) add that, in their study of retail stores in Copenhagen, Denmark, receivers can influence delivery times when goods are distributed via UCCs. In effect, fewer deliveries and an increased awareness of delivery times can improve planning in regard to retail-store staff and increase the possibility that all personnel can focus on their core tasks: selling products rather than managing in-store logistics activities (Browne et al., 2005; Aastrup et al., 2012). Thereby, changes in delivery patterns can result in reduced costs for receivers and may increase receivers’ delivery services.

A UCC can also offer receivers value-added services, such as additional stockholding, pre-retail activities, handling of reverse logistics, home delivery, and ordering processes (Browne et al., 2005; van Rooijen and Quak, 2010; Aastrup et al., 2012; Allen et al., 2012); most of those 
services could facilitate the in-store logistics activities. In that context, stockholding implies that the UCC has storage space that receivers can rent-for example, to reduce the amount of storage space in the store and thereby increase sales areas (Aastrup et al., 2012). Furthermore, since the rent — that is, the value of the property — is normally far greater in commercial areas than in industrial ones where UCCs are commonly located (Lin et al., 2014), a great deal of money can be saved by relocating storage space. Browne et al. (2005) add that storage at UCCs can also act as a buffer during seasonal peaks. Moreover, UCCs can offer services related to pre-retail activities, including unpacking, price tagging (Browne et al., 2005), and attaching antitheft devices (Aastrup et al., 2012). Meanwhile, reverse logistics includes handling returns and recycling packaging materials, which are other examples of value-added services that UCCs can offer (Browne et al., 2005). In their investigation of potential receivers' interests in value-added services, Aastrup et al. (2012) found that the three most popular services were the attachment of antitheft devices, access to external storage, and the return of packaging materials. Interestingly, the benefit of being able to return packaging materials was deemed twice as great as the other two combined.

To put receivers of UCCs in the context of this study, the potential benefits for retail stores that use a UCC will be further elaborated below. By extension, several in-store logistics activities that take place within retail stores can be executed at UCCs instead. Kotzab and Teller (2005) identified several activities that are performed in retail stores, e.g. delivery and reception, transport to shelves or temporary backroom storage, storage in the backroom itself, transports from backroom storage to shelves, handling and preparatory activities, reordering, and disposal and recycling. The extent of those activities is not to be underestimated. In their study of one of Sweden's largest grocery retail supply chains, Saghir and Jönson (2001) found that 75\% of all handling times in the retail chain occurred within the store. van Zelst et al. (2009) further identified in-store handling costs to be the largest costs in the entire retail supply chain. Aastrup 
et al. (2012) have argued that several of these in-store logistics activities, including storage, preparatory activities, and displays, should be considered for relocation to the UCC. They add that simpler activities such as price-tagging and attaching antitheft devices are also suitable for performing at a UCC. In addition, they found in their study that, by using a UCC, the personnel at stores could spend more time helping customers (Aastrup et al., 2012), i.e. providing better customer service.

Simply put, a retail store serviced by a UCC can focus on its core activity: to provide customer service at the store. Customers' in-store experiences of interactions with personnel and the accessibility of the store space were identified early on as aspects important to customers (Westbrook, 1981). In their analysis of a survey of customers at three large shopping malls, Hosseini et al. (2014) detected a positive, significant relationship between service, expressed as employee-customer interactions, for example, and customers' perceptions of in-store services.

However, if retail stores are to contribute to financing a UCC, they also need to perceive value for the services that they can receive. Aastrup et al. (2012) have asserted that one reason for the lack of success of urban logistics initiatives might be the disregard for receivers' requests and expectations: "A characteristic of this literature is that it identifies certain activities possible to provide but does not address the users’ perspective” (Aastrup et al., 2012, pg. 7).

\section{Summation of the literature review}

To summarize the literature review, a UCC has the potential to have a significant positive impact on a city in terms of improved social and environmental factors. However, previous experiences point to problems regarding the financial aspects of the cost of a UCC, and in the past, they have often failed to generate enough revenue. Receivers are probably the segment of stakeholders who could benefit the most (except for the city itself) from using a UCC. A UCC 
can influence delivery times, delivery frequencies and provide UCC-services and the store personnel can thereby focus on delivering service to their customers (Aastrup et al., 2012; Browne et al., 2005). Thus, stores with deliveries on preferred times and/or less delivery frequencies ought to experience a more satisfying customer service as well as a lower need for supporting UCC services that can reduce the need for the stores to manage in-store logistics activities.

Figure 1 below illustrates the balancing of the costs associated with a UCC with the benefits it can provide, in this study, the benefits for retail stores. Potential service offerings can be based on a combination of value-added services and/or logistics services.
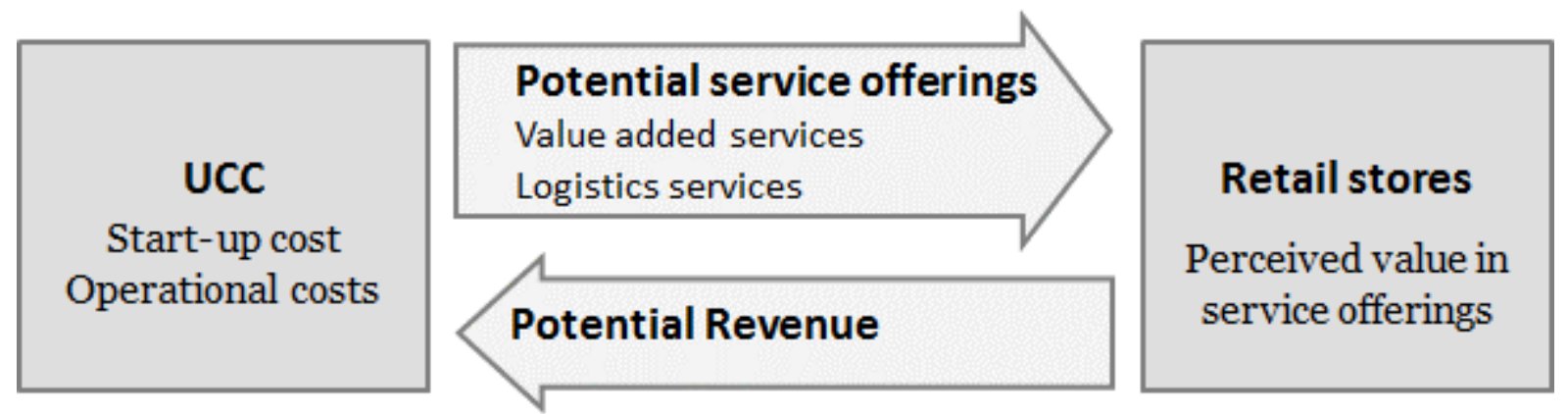

Figure 1. Balancing the cost and the benefits of a UCC.

To summarize the identified gaps in current literature: an often missing perspective is the perspective of the receivers of goods, another gap is on how a UCC can affect the customer services in retail stores as well as reducing costs. These are also the research gaps we aim to address in this study.

\section{Methodology}

The overall design of the study was largely influenced by other studies on the topic (e.g. van Duin et al., 2010; Aastrup et al., 2012). In this study, empirical data were collected by 
conducting numerous structured interviews with retail-store personnel. Interviews were chosen instead of surveys in order to increase the response rate and to have the possibility, if needed, to ask questions in order to clarify respondents’ open comments.

\section{Sample selection}

Browne et al. (2005) have argued that there is a greater possibility of introducing a UCC to supply a shopping mall than to supply a specific urban area. Accordingly, we chose to study retail stores located in city malls, and thus we selected six malls in the Swedish cities of Linköping and Norrköping. In those malls, a total of 72 interviews were conducted with store personnel.

To increase potential respondents' willingness to participate, we first targeted a spokesperson for the companies responsible for each mall and explained the benefits of our study and the importance of including retailers' perspectives in urban logistics. All representatives were positive towards the study and informed their respective stores that in-store personnel would be interviewed. As a result, most personnel were willing to participate as long as the interviews did not interfere with their daily work. During interviews, one employee typically answered all the questions; occasionally, multiple employees were involved, especially if they perceived a need for other employees to participate in the interview because of their different responsibilities and knowledge regarding the need for different in-store logistics activities. There were always two interviewers present; one asked the questions, while the other took notes.

Not all stores in the six malls were included. As the aim was to explore retail stores, other businesses including restaurants, cafés, and kiosks were excluded due to the lack of in-store logistics activities performed by these businesses. In addition, stores whose goods were not conducive to being supplied through a UCC were excluded—for example, expensive jewellery 
and watches, alcohol (Sweden has a monopoly and specific stores, "Systembolag”, for alcohol), and drugs for pharmacies. Moreover, these stores have additional security during deliveries, and delivery times are undisclosed. Aside from the stores excluded from our study, several others chose not to participate, primarily due to lack of time, although some companies claimed to have a policy that prohibited employees from answering the types of questions included in the interviews. At a certain point near the end of the data collection, we noted saturation in our answers and, therefore, did not see any need to include additional stores, in accord with the guidance of Bryman and Bell (2015) that, when new data do not provide new information, saturation has been reached. The percentage of respondents in malls in Norrköping was less than in Linköping, due to one of two reasons if not both. First, it was more difficult to access available personnel in Norrköping due to a larger number of shoppers there. Second, during the interviews, we noticed that stores belonging to the same retail chain reported nearly identical answers, which suggested that we had also attained data saturation from this direction, and thus we disregarded several stores in Norrköping. It should be noted that the interviews in Norrköping were conducted last. The number of respondents at each mall is shown in Table 1.

Table 1. Number of respondents at each city mall and the total number of stores in each mall

\begin{tabular}{lccc|ccc}
\hline & \multicolumn{3}{c|}{ Linköping } & \multicolumn{3}{c}{ Norköping } \\
\hline Mall & Mall A & Mall B & Mall C & Mall D & Mall E & Mall F \\
Number of & 15 & 11 & 21 & 13 & 7 & 5 \\
interviews & & & & & & \\
Number of & 22 & 12 & 35 & 38 & 19 & 17 \\
stores & & & & & & \\
\end{tabular}


We targeted the personnel working in the stores in order to investigate how they worked and the problems they experienced related to logistics activities. Even though managers and other administrative staff have greater power to implement changes, shop personnel are more likely to have insights regarding operational activities and problems related to, e.g. inventory control, preparation of products, and goods receptions, that can be targeted by potential UCC services. It is the understanding of these activities that can provide us with insights regarding why retail stores could potentially be interested in UCC services.

\section{Design of interview questions}

Neither before nor during interviews were respondents informed of the context of the interview questions, i.e. UCCs were never mentioned. This decision was made because the interviews aimed to investigate only how personnel worked and what problems they experienced and not their perceptions or attitudes towards UCCs. Furthermore, as the personnel had limited time available for the interviews, we did not want to spend time on explaining a rather complex logistics solution.

The interview protocol comprised 10 questions; see Appendix. The interview began by verifying that the respondent had experience handling goods at arrivals but also a significant degree of contact with customers in the stores (thus, the focus activity of store personnel - to provide customer service). In order to ensure content validity, the questions were based on the literature review. For example, the potential of a UCC to consolidate consignments, thereby resulting in fewer deliveries, and generating fewer interruptions for store personnel (e.g. Browne et al., 2005; Aastrup et al., 2012) were targeted by asking a question about the extent that goods reception hindered the personnel from focusing on, e.g. interacting with customers to increase customer service. The questionnaire was designed to support a structured interview, with predetermined questions and order of questions, see appendix. The questions were designed so that participants could respond with short answers (e.g. yes/no, stating a number, 
or by naming an activity), but respondents were also allowed to add commentary to each answer in order to explain themselves in greater detail. For some questions, we applied open answers and encouraged alternative answers. One reason for allowing open answers was to enable us to identify patterns in the empirical data since results from previous research have, to some extent, been divided concerning, e.g. preferable delivery times. For instance, Aastrup et al. (2012) have stated that stores prefer delivery times early in the day, whereas van Duin et al. (2010) advocated not having personnel in the store before opening hours, thereby arguing for deliveries during opening hours instead. Some of their more open comments were also used in the empirical description as it provided a deepened understanding to their situation and why, or why not they e.g. perceived some needs or problems.

\section{Data analysis}

The authors of the article played different roles in the design, collection, and analysis of the data. Investigator triangulation (see, e.g. Patton, 2002) was applied, as at least two persons were present at all stages. The first step of the data analysis involved identifying congregated periods for current and preferred delivery times. As Miles et al. (2014) state: data condensation is a part of the analysis, and in order to provide a clearer overview of the data. Guided by the periods suggested in the literature thus "early in the day" (Aastrup et al., 2012) and "when the stores are opened” (van Duin et al., 2010) we manually identified respondents in favour of both these categories but also in opposition thus had or preferred deliveries during the entire day as well as before the store opened. However, no respondent had or preferred deliveries after the store had closed.

The delivery frequencies were also manually clustered to provide an overview of the empirical data. For respondents who stated an interval (e.g. three to six deliveries per day), we used mean values. In the case of uneven mean values, the lower boundary was always chosen to illuminate 
a less-optimistic view of potential UCC services. For instance, Aastrup et al. (2012) found that receivers deemed fewer deliveries to be beneficial.

Our analysis aimed to establish retail stores’ potential demand for UCC services by first exploring whether they had experienced any problems with the daily work involving different logistics activities and if that work had affected the customer service provided. Second, we investigated their need for or interest in assistance with activities that could be provided by a UCC. In other words, our analysis, with support from our literature review, was based on identifying gaps between current problems and the stores' interest in and needs for resolving them.

To test if our data supported the literature suggesting that fewer deliveries can influence the level of customer service, as well as the need for additional UCC services to reduce the amount of in-store logistics activities, independent sample $t$-tests were applied (Hair et al., 2006). The delivery frequencies were divided into two groups (high and low). The analysis was conducted two times by applying different division values: more or fewer than three or four deliveries (i.e. excluding respondents with three or four deliveries). Deviation values were selected to form two groups of similar size, and responses that overlapped the deviation values, e.g. "2-4 deliveries”, were excluded. Independent sample $t$-tests were also applied to test if the stores receiving goods at non-preferred times of the day experienced a higher demand for UCC services or whether in-store logistics activities influenced customer service in a negative way.

\section{Empirical findings}

\section{Delivery time}

Table 2 shows the 72 stores' current and preferred delivery times. Respondents' answers were likewise spread widely, and answers were congregated to facilitate a clearer overview of the results. Aside from the predetermined category 'At opening', we identified that all remaining 
answers could be classified within three time intervals: 'Before opening', 'In the morning (i.e. 10-12 am)', and 'Throughout the day (i.e. from opening to closing)'. The most common current time interval for deliveries was 'Throughout the day' $(n=30)$, while the second-most common was 'In the morning' $(n=25)$. The remaining 17 stores received deliveries before or upon opening. Most stores that have chose the delivery times themselves (e.g. when receiving deliveries from their own central warehouses) received deliveries before or upon opening.

When asked about preferred delivery times, only 3 stores stated that they did not have any preference. All other stores preferred deliveries any time in the morning $(n=23)$, upon opening ( $n=21$ ), or before opening ( $n=17)$. Table 2 also indicate (within brackets) that most stores that currently receive goods in the morning prefer the exact same delivery time as they currently have, while only 9 of the 30 receiving goods during the entire day prefer this time interval.

Table 2. Number of stores that stated the delivery time for current and preferred delivery times

\begin{tabular}{ccc}
\hline & $\begin{array}{c}\text { Current delivery time (exact } \\
\text { same current as preferred time) }\end{array}$ & Preferred delivery time \\
\hline Before opening & $11(9)$ & 21 \\
Upon opening & $6(5)$ & 23 \\
During the morning & $25(18)$ & 11 \\
Throughout the day & $30(9)$ & \\
\hline
\end{tabular}

\section{Delivery frequency}

Most stores had a delivery frequency of 5 deliveries per week or fewer, meaning 1 delivery per day at most. There were no deliveries during weekends. Therefore, we set the intervals of 
delivery frequency to 1 (or less than 1), 2, 3, 4, 5, and more than 5 deliveries per week. The delivery frequency is presented in the same order as the intervals: 12 stores in the 1 (or less) interval, 8 stores with 2 deliveries a week, 4 stores with 3 deliveries a week, 13 stores with 4 deliveries a week, and 18 stores with 5 deliveries a week. Of the number of respondents in the $>5$ category, which was represented by 17 stores, the personnel in 3 stores stated that they had 10-15 deliveries per week; another 3 stores had 10 deliveries per week; and the rest reported 5-10 deliveries per week.

Unlike the case in regard to delivery times, most stores’ personnel did not state any preference regarding delivery frequency. Interestingly, however, several stores’ personnel stated that they would like to increase the frequency of deliveries. In those cases, deliveries occurred weekly or once every other week, i.e. '1 delivery (or less than 1) per week'.

\section{In-store logistics activities}

In all, 12 stores' personnel stated that the reception of goods negatively affected their ability to provide the highest-quality customer service possible. However, as both observed and commented on by some personnel, if they were busy when deliveries arrived, the carrier would simply wait until reception could be accomplished—sometimes up to 5 minutes. A few stores described that they increased their workforce when they expected deliveries-for instance, stores with only one delivery per week. If personnel were busy at the time of delivery, unpacking was postponed or, in some cases, unpacked goods were left in the sales area. A few stores even had specific warehouse personnel, meaning that in-store personnel were not involved in the reception of goods.

Regarding in-store logistics activities, 22 stores’ personnel stated that their ability to provide the best customer service possible was hindered. Of these, personnel of 12 stores cited examples of logistics activities that sometimes hindered their provision of customer service, such as 
attaching antitheft devices $(n=4)$, unpacking goods $(n=4)$, price-tagging $(n=2)$, and handling packaging materials $(n=2)$. Many stores’ personnel reported having enough time to perform in-store logistics activities in between helping customers, and one store's personnel commented that, even if they were prepared to drop what they were doing in order to assist a customer, the customer might perceive that personnel were busy and might not ask for help. Personnel for at least two stores mentioned that recording received goods in the computer system was a highly time-consuming activity.

In addition, 42 stores' personnel expressed a need for additional storage space. Of those stores, 7 reported needing additional storage room during seasonal changes or peak seasons (e.g. Christmas). For clothing stores, those periods were characterised by major changes in product assortments, which resulted in a greater need for storage space and also meant more timeconsuming in-store logistics activities.

By bundling the requests change of delivery time, interest in getting help with logistics activities, and need for additional storage, a total of 59 stores showed interest in at least one of them. Since personnel at some stores reported more than one problem, the remaining 13 did not perceive that the reception of goods or in-store logistics activities negatively affected their ability to provide customer service and did not express a need for additional storage space. Table 3 shows the number of stores that identified each alternative as a problem. That number could be even greater, since personnel at several stores did not express any interest in the services that a UCC could provide because of the potential costs involved, as they expressed during interviews. 
Table 3. Number of stores with perceived problems (that could be addressed by potential UCC services)

\begin{tabular}{lccccc}
\hline & $\begin{array}{c}\text { Reception of } \\
\text { goods }\end{array}$ & $\begin{array}{c}\text { In-store } \\
\text { logistics }\end{array}$ & Insufficient & Delivery time & No \\
& & storage & & identified \\
& 3 & 6 & 8 & 7 & 1 \\
Mall A & 3 & 2 & 4 & 7 & 1 \\
Mall C & 0 & 3 & 14 & 5 & 6 \\
Mall D & 2 & 5 & 9 & 5 & 2 \\
Mall E & 3 & 4 & 4 & 3 & 1 \\
Mall F & 1 & 2 & 3 & 0 & 2 \\
\hline Total & 12 & 22 & 42 & 27 & 13 \\
\hline
\end{tabular}

\section{Analysis and discussion}

As Marcucci and Danielis (2007) state, the cost of using a UCC — in our study, the stores' costs for purchasing UCC services-needs to be less than the cost reduction it may yield (from the perspective of retail stores). With support from the frame of reference, we have identified at least two arguments for why a retail store could be willing to participate in financing a UCC. First, the literature suggests that the use of UCC services might increase the stores' capacities to improve customer service. Second, it is possible that cost savings could be achieved. Whether our study supports these two arguments is further discussed in the two sections below. The 
section ends with a discussion of what types of services a UCC can provide that stores might be interested in.

\section{UCCs and improved customer service}

Several stores’ personnel stated that their ability to provide the best customer service possible was obstructed by in-store logistics activities $(n=22)$ and the reception of goods $(n=12)$. Of the 72 stores, 12 provided examples of logistics activities that sometimes hinder their provision of customer service. One of the more common obstructive activities was 'Unpacking products', an activity that cannot completely be shifted to a UCC since products require their packaging during transport from the UCC to the store. The activity that personnel at four of the stores cited as having potential to be performed by some other actor was attaching antitheft devices.

Furthermore, independent sample $t$-tests did not identify any significant relations that could confirm that stores with non-preferred delivery times or higher delivery frequencies were more hindered in providing customer service or the ones experiencing a need that can be targeted with a UCC service to a larger extent. Table 4 illustrates, applying crosstabs, the distribution of the stores among these aspects as well as the p-values provided from the t-test. However, we interpret that the lack of significant relations indicates that the problem and the relationships that we investigated are very complex. Preferable delivery frequencies, for example, can be dependent on a number of variables, such as types of products and size of the store.

Table 4. Cross tabs and t-test

\begin{tabular}{|c|c|c|c|c|}
\multicolumn{2}{|c|}{$\begin{array}{c}\text { Hindered in providing } \\
\text { customer service }\end{array}$} & $\begin{array}{c}\text { Have a need that can } \\
\text { be targeted with a } \\
\text { UCC service }\end{array}$ & \\
\cline { 1 - 2 } Yes & No & Yes & No & Sum \\
\hline
\end{tabular}




\begin{tabular}{|c|c|c|c|c|c|c|c|}
\hline \multirow[t]{3}{*}{ Cross tab } & \multirow{2}{*}{$\begin{array}{l}\text { Current and } \\
\text { preferable delivery } \\
\text { times are the same }\end{array}$} & Yes & 3 & 39 & 13 & 29 & 42 \\
\hline & & No & 7 & 20 & 7 & 20 & 27 \\
\hline & \multicolumn{2}{|l|}{ Sum } & 10 & 59 & 20 & 49 & 69 \\
\hline T-test & \multicolumn{2}{|l|}{ Sign. (2 tailed) } & 0,031 & & 0,659 & & \\
\hline \multirow[t]{3}{*}{ Cross tab } & \multirow{2}{*}{$\begin{array}{l}\text { No of deliveries a } \\
\text { week }\end{array}$} & $<4$ & 3 & 18 & 7 & 14 & 21 \\
\hline & & $>4$ & 5 & 29 & 9 & 25 & 34 \\
\hline & \multicolumn{2}{|l|}{ Sum } & 8 & 47 & 16 & 39 & 55 \\
\hline T-test & \multicolumn{2}{|l|}{ Sign. (2 tailed) } & \multicolumn{2}{|c|}{0.967} & \multicolumn{2}{|l|}{0.594} & \\
\hline
\end{tabular}

In examining respondents' comments, we offer explanations for why several stores did not experience any problems in providing customer service or see a need for potential UCC services: carriers had to wait if personnel were busy (sometimes up to 5 minutes); deliveries were left in boxes in the store if personnel had limited time to unpack them; and the workforce was increased on the day of delivery. An interesting factor raised by one store's personnel is the importance of considering how customers experience the store. Decreased accessibility due to goods placed in the store, for example, could influence customers' willingness to shop there. As Westbrook (1981) pointed out early, accessibility to storage space is an important aspect for customers, since they might perceive personnel to be busy and thus not ask for help and perhaps even make their purchases at another store. So, although it is commonly mentioned in the literature (see e.g. Browne et al., 2005; Aastrup et al., 2012) that a UCC could improve retail stores customer service, our results contradicts this. The stores have in many cases worked out methods of dealing with apparent problems, however, the effectiveness of these solutions can be questioned.

\section{Potential cost reduction by using UCC services}

Personnel at numerous stores stated that they might be interested in the services that a UCC could provide, yet they feared the cost of those services. Costs were not mentioned in any of 
the interview questions. Despite this, the respondents did fear the costs that would result from outsourcing these activities to another actor. To be able to elucidate the potential of cutting costs, there is a need to address this aspect from a more holistic perspective than the respondents do. For instance, receivers do not perceive the costs of making carriers wait. Even though the stores were not bothered by carriers having to wait, it is important to scrutinise how that wait affects the larger system. For one, carriers' delivery route-times will increase, especially if multiple stores make them wait. At the same time, carriers' vehicles must then be parked, perhaps on a public square or narrow shopping street; even if the freight vehicle is parked at a loading dock, it may cause queues for other vehicles at the dock. Moreover, some actor has to pay for the wait—namely, the transport purchasing company. Thus, either directly or indirectly (e.g. increased prices for products purchased), retail stores indeed pay a cost for making carriers wait. The above discussion is also in line with Allen et al. (2012), who state that how to allocate the costs and benefits of a UCC solution, and not solely the cost impact on the part of the supply chain or a single player, is a key consideration.

Despite the sometimes-inconvenient delivery times for goods, these stores have found solutions that enable them to focus on providing a high level of customer service; however, they might not see the actual cost of those solutions. By increasing the workforce to cope with deliveries and in-store logistics activities, for example, or always having multiple personnel present at the store to cope with both in-store logistics activities and customer service, stores are already paying the cost, even if they do not recognise it. It is quite plausible that outsourcing some activities to a UCC might thus benefit stores. If several stores express the same type of service needs, a potential to gain large-scale economic advantages arises by moving these activities to a UCC. For example, not all stores would need the equipment and knowledge necessary to attach antitheft devices if this activity could be carried out in the UCC. Due to large-scale advantages of UCCs, the costs ought to decrease if these types of activities are performed within 
UCCs. If there is a potential for the retail store to reduce its costs, it represents a strong argument for why they would pay for the services. In line with the reasoning of Marcucci and Danielis (2007), it is thus crucial for the cost of using a UCC to be less than the potential reduction in cost that it might yield.

\section{UCC services that retail stores might be interested in}

Several potential UCC services cited in the literature as being of interest to retail stores have been investigated. Personnel at 59 of the 72 stores included in the present study showed some interest in services that can potentially be provided by a UCC. Here, it is important to keep in mind that we did not ask about the need for a particular service directly but more as an openended question of "which types of services". Thus, the need for the services is likely to be even greater than described below. Furthermore, in order to gain the large-scale economic advantages from moving an activity from the store to the UCC, it must be needed by several stores. The retail stores’ demands for various UCC services are further elaborated on below.

Storage. Contrary to other UCC services, most stores $(n=42)$ requested external storage. Interestingly, only 7 of these stores would use storage during seasonal peaks, meaning that the remaining 35 stores were interested in using that storage permanently. Although the numbers are not comparable, Aastrup et al. (2012) also found storage to be one of the most-requested UCC services.

Time of delivery. The stores investigated preferred that deliveries arrived either around the time of opening or in the morning. Earlier deliveries might enable the stores’ personnel to perform most of the in-store logistics activities during the morning, when the number of customers is not as large and personnel have more time for customers when they do arrive. Of the 72 stores, 37 requested deliveries to arrive upon opening, if not before, which contradicts the finding of van Duin et al. (2010), who state that not receiving goods before opening hours is a benefit due 
to the time saved on personnel costs. However, those researchers neglected to mention that the time prior to the store's opening can be used for value-creating activities (e.g. in-store logistics activities). Our study thus not only provides knowledge regarding current and preferred delivery times, but by including questions that allowed open answers, it also identified one of the mostdesirable delivery times: upon opening. However, even if that time is one of the most preferred, it is not possible for logistics service providers to deliver to all stores simultaneously. Also notable is that no respondent mentioned a need for more reliable delivery times, as Browne et al. (2005) and Aastrup et al. (2012) have.

Decrease of delivery frequencies. In the literature (e.g. Aastrup et al., 2012), the decrease in delivery frequencies is described as a value created by the UCC due to more-consolidated shipments. There is, therefore, a potential for receivers to be interrupted less often in the course of their daily activities. However, our respondents did not perceive high delivery frequencies as posing a problem. On the contrary, some stores with very few deliveries per week would appreciate more deliveries.

Recording in the computer system. This task was also identified as a potential UCC service that we could not find in the literature. Personnel at two stores mentioned that recording goods received in the computer system was a highly time-consuming activity. This work could also be considered a type of low-skill activity, as Aastrup et al. (2012) put it, suitable for performing at a UCC. However, in reality, it could be difficult to operationalize the task since stores use different systems.

Return handling. This UCC service was identified as one of the most frequently requested by Aastrup et al. (2012). However, only two of our respondents indicated that the packaging materials, packages, or load units, among other things, were problems. It could be that they neglected this aspect, since we did not offer any examples of potential problems or benefits along those lines in our interviews. However, if this activity represented as large a problem as 
in the Danish study, then, most likely, it would have been mentioned. Explanations for the contradictory findings might be that the studies were conducted in different countries; alsoand perhaps even more likely_our stores were located in city malls. City malls often have more-systematic ways of handling the return of packaging materials with containers for used materials located in the building or nearby.

\section{Conclusions, contributions, and future research needs}

Despite the many benefits of UCCs for urban populations and the environment, examples of viable UCCs continue to be scarce, due primarily to their lack of economic viability. In this study, we have taken a point of departure by seeking to identify argument why retail stores would be interested, by the use of UCC services, to be a part of the financing of a UCC. We contribute with the perspective of the receivers, a stakeholder group often mentioned in the city logistics literature (see e.g. van Rooijen and Quak, 2010) but very seldom targeted in the city logistics research. The retail stores in this study are located in city malls. However, the conclusion is also valid in other contexts since most in-store logistics activities are not dependent on stores being located within a mall. We have not found any arguments why our overall findings are specific to a Swedish context and therefore our conclusions ought to have an external validity also outside a Swedish context. It should be noted that the potential demand for UCC services could be even greater, because retail stores were excluded in the study due to their lack of time. This also applies to arguments regarding both potential improved customer service and potential cost reduction. To some degree, it is a paradox that those stores that ought to have the most to gain from implementing a UCC are the most difficult to include in this kind of study.

Two overall arguments for why a retail store could be willing to participate in financing a UCC have been identified in the literature: the use of UCC services might increase the store's 
capacity to improve customer service, and it is possible that cost savings could be achieved when activities are moved from the store to the UCC.

Our findings indicate that the potential to further improve customer service at retail stores might not be achieved with the implementation of a UCC, and therefore, the potential for increased income is not the strongest argument for retail stores to pay for UCC services. It seems that retail stores have found solutions that allow them to maintain the level of customer service that they seek; however, it remains unclear how cost-effective those solutions actually are, and this constitutes a question that needs to be addressed in future research. Our findings, therefore, challenge the existing literature arguing that a UCC could improve stores' customer service (c.f. Aastrup et al., 2012). To more precisely determine whether a UCC can improve customer service, more-probing studies are needed, especially those aimed at grasping the perspectives of customers.

We have identified that the stores investigated expend a great amount of their resources on logistics activities more or less consciously and that cost savings could be achieved if these activities were covered by UCCs. Economic advantages can be found by, e.g. offering additional storage in areas with lower rental costs or moving logistics activities to the UCCs in order to gain large-scale advantages. Our findings thereby point to a need for understanding the actual logistics demands of stores as well as the potential for gaining economic advantages by moving services needed by several stores to a UCC. However, how large scale these must be before large-scale economic advantages are realized in the transfer of activities is a question to be investigated by further research. Furthermore, store personnel see the costs of activities carried out by external actors, but not to the same extent that they see the costs of their own internal solutions for maintaining a high level of customer service, in spite of in-store logistics activities that may disrupt service. Our study reveals the need to underscore the economic value of these solutions in order to advocate for the potential benefits of outsourcing activities to 
UCCs. And, adding to this, if we consider the larger system, e.g. a number of stores stated that the carrier had to wait, stores probably pay indirectly for this in increased price for transports. However, retailers do not perceive these activities as posing a cost. To summarize, the results of our study contribute to both research and practice, as they underscore the importance of a cost-oriented mind-set — namely, that of store managers who need to be aware of cost allocation and the benefits in terms of cost savings.

Our study also demonstrates the importance of investigating the need for different UCC services in the planning phase of UCCs. Needs vary widely depending on a store's present situation. Not only does our study identify needs, or the lack thereof, that contradict what has been identified in other studies, but in addition, we see somewhat different demands in the stores that we investigated. For example, a demand for assistance with handling packing materials and a demand for more-reliable deliveries were not found in this study, contrary to the findings of Browne et al. (2005) and Aastrup et al. (2012).

Retail stores might not be the only actors who should finance UCCs. When identifying potential revenue streams for UCCs, it is important to identify all potential customers. The city and its inhabitants have much to gain from the implementation of a UCC. Very few studies have expressed the benefits of a UCC in quantified external costs. Increased consideration of the environmental and social benefits expressed in terms of decreased external costs in future research could actually act as an important argument for the potential UCC customer, "the city", (in terms of local authorities and inhabitants) to participate in the funding of a UCC. The difference with the city financing the UCC, compared to previous studies, is that by quantifying external cost, stronger arguments arises why the city (and possibly the inhabitants) should pay for it. Furthermore, by providing calculated external costs (that a UCC might reduce) the UCC can be viewed as a service to the city and its inhabitants. E-commerce customers represent another potential source of UCC users that are important to consider as future financiers of 
UCCs. The role of UCCs as enablers in this development is an interesting area for future research. Another actor that might benefit from the use of a UCC, and thus could be a financier, is the logistic service provider (LSP). However, although several actors might participate in financing the cost for a UCC, we must keep in mind that the receivers represent the segment of actors with the most to gain if the UCC is designed to meet their demands.

Furthermore, because of how we designed the interviews, in particular not mentioning the kinds of city logistics solutions targeted (the UCC), our findings can also be relevant to other city logistics solutions that have potential to provide similar services, such as post boxes used by stores and the purchasing of value-added services from the LSPs. Post boxes can be emptied when store personnel have time, reducing the risk that products are left in stores, which could affect customers' perceptions of stores. An LSP could potentially also provide value-added services, e.g. attaching antitheft devices and price-tagging. However, all of the stores' LSPs would probably have to offer the same types of services in order to provide a uniform appearance, and that could be difficult to coordinate.

\section{Acknowledgement}

We thank VINNOVA, Sweden's Innovation Agency, for financing the project "Business Models for City Logistics", in which this paper is a part. We would also like to thank master student Jacob Bergvall for his support during the empirical data collection.

\section{References}

Aastrup, J., Gammelgaard, B. \& Prockl, G. (2012), "3PL services in city logistics - A user's perspective", Proceedings of the 24th annual nordic logistics research network conference.

Allen, J., Browne, M. \& Holguín-Veras, J., (2015). "Assessing the environmental impacts of freight transport". In A. Mckinnon, M. Browne, M. Piecyk \& A. Whiteing (eds.) Green logistics - Improving the environmental sustainability of logistics. 3 ed. Kogan Page: London.

Allen, J., Browne, M., Woodburn, A. \& Leonardi, J. (2012), "The Role of Urban Consolidation Centres in Sustainable Freight Transport", Transport Reviews, 32, 473-490. 
Allen, J., Browne, M., Woodburn, A. \& Leonardi, J. (2014), "A review of urban consolidation centres in the supply chain based on a case study approach", Supply Chain Forum, 15, 100-112.

Bestufs, (2007). Best Urban Freight Solutions II: Road pricing and urban freight transport, Urban freight platforms, Best practice handbook [online]. http://www.transportresearch.info/sites/default/files/project/documents/20100302_171621_79418_BESTU FS II_Good_Practice_Guide on urban freight transport.pdf [Accessed: 2017-03-23].

Björklund, M. \& Gustafsson, S. (2015), "Toward sustainability with the coordinated freight distribution of municipal goods", Journal of Cleaner Production, 98, 194-204.

Browne, M., Allen, J. \& Leonardi, J. (2011), "Evaluating the use of an urban consolidation centre and electric vehicles in central London", IATSS Research, 35, 1-6.

Browne, M. \& Gomez, M. (2011), "The impact on urban distribution operations of upstream supply chain constraints", International Journal of Physical Distribution \& Logistics Management, 41, 896-912.

Browne, M., Sweet, M., Woodburn, A. \& Allen, J. (2005), "Urban Freight Consolidation Centres Final Report".

Bryman, A. \& Bell, E., (2015). "Business research methods" Oxford University Press: Oxford, UK.

Hair, J.F., Black, W.C., Babin, B.J., Andersson, R.E. \& Tatham, R.L., (2006). "Multivariate data analysis" Pearson Prentice Hall: Upper Saddle River, NJ.

Hosseini, Z., Jayashree, S. \& Malarvizhi, C. (2014), "Store Image and Its Effect on Customer Perception of Retail Stores", Asian Social Science, 10, 223-235.

Kotzab, H. \& Teller, C. (2005), "Development and empirical test of a grocery retail instore logistics model", British Food Journal, 107, 594-605.

Liimatainen, H., Hovi, I.B., Arvidsson, N. \& Nykänen, L. (2015), "Driving forces of road freight CO2 in 2030", International Journal of Physical Distribution \& Logistics Management, 45, 260-285.

Lin, J., Chen, Q. \& Kawamura, K. (2014), "Sustainability SI: Logistics Cost and Environmental Impact Analyses of Urban Delivery Consolidation Strategies", Networks and Spatial Economics, 16, 227-253.

Malhene, N., Trentini, A., Marques, G. \& Burlat, P. (2012), "Freight consolidation centers for urban logistics solutions: The key role of interoperability", IEEE International Conference on Digital Ecosystems and Technologies.

Marcucci, E. \& Danielis, R. (2007), "The potential demand for a urban freight consolidation centre", Transportation, 35, 269-284.

Miles, B.M., Huberman, A.M. \& Saldaña, J., (2014). "Qualitative Data Analysis - A Methods Sourcebook", 3 ed. Sage Publications Inc: Thousand Oaks.

Muñuzuri, J., Larrañeta, J., Onieva, L. \& Cortés, P. (2005), "Solutions applicable by local administrations for urban logistics improvement", Cities, 22, 15-28.

Nordtømme, M.E., Bjerkan, K.Y. \& Sund, A.B. (2015), "Barriers to urban freight policy implementation: The case of urban consolidation center in Oslo", Transport Policy, 44, 179-186.

Quak, H., (2011). "Urban freight transport: the challenge of sustainability" Edward Elgar Publishing: Cheltenham, UK.

Quak, H., Balm, S. \& Posthumus, B. (2014), "Evaluation of City Logistics Solutions with Business Model Analysis", Procedia - Social and Behavioral Sciences, 125, 111-124.

Rao, C., Goh, M., Zhao, Y. \& Zheng, J. (2015), "Location selection of city logistics centers under sustainability", Transportation Research Part D: Transport and Environment, 36, 29-44. 
Saghir, M. \& Jönson, G. (2001), "Packaging handling evaluation methods in the grocery retail industry", Packaging Technology and Science, 14, 21-29.

United Nations Department of Economic and Social Affairs, (2014). World Urbanization Prospects: The 2014 Revision, Highlights [online]. http://esa.un.org/unpd/wup/highlights/wup2014-highlights.pdf [Accessed: 2017-0323].

Van Duin, J.H.R., Quak, H. \& Muñuzuri, J. (2010), "New challenges for urban consolidation centres: A case study in The Hague", Procedia - Social and Behavioral Sciences, 2, 6177-6188.

Van Rooijen, T. \& Quak, H. (2010), "Local impacts of a new urban consolidation centre - the case of Binnenstadservice.nl", Procedia - Social and Behavioral Sciences, 2, 59675979.

Van Zelst, S., Van Donselaar, K., Van Woensel, T., Broekmeulen, R. \& Fransoo, J. (2009), "Logistics drivers for shelf stacking in grocery retail stores: Potential for efficiency improvement", International Journal of Production Economics, 121, 620-632.

Ville, S., Gonzalez-Feliu, J. \& Dablanc, L. (2013), "The Limits of Public Policy Intervention in Urban Logistics: Lessons from Vicenza (Italy)", European Planning Studies, 21, 1528-1541.

Westbrook, R.A. (1981), "Sources of consumer satisfaction with retail outlets", Journal of retailing, 57, 68-85. 


\section{Appendix}

Interview questions (translated from Swedish):

- How many deliveries do you receive each week? Is this too few/too many times?

- At what time of the day do you receive goods?

- Do the number of deliveries hinder you from providing the best customer service possible?

- Do the time of delivery hinder you from providing the best customer service possible?

- If the service level is maintained, do you have any comments regarding the strategies used in order to maintain a high level of service?

- At what time would you prefer to receive goods?

- Do activities related to the handling of goods (in-store logistics activities) hinder your ability to provide the best customer service possible?

o If yes, which activities hinder this ability?

o If no, do you have any comments regarding strategies to handle the goods in order to maintain a level of customer service?

- If you got assistance with the activities (in-store logistics activities), would you be able to provide better customer service?

- Do you find a need for more storage space? 